\title{
Product lifecycle management in knowledge intensive collaborative environments: An application to automotive industry
}

\author{
Filipe Ferreira $^{\mathrm{b}, *}$, José Faria ${ }^{\mathrm{a}, \mathrm{b}}$, Américo Azevedo ${ }^{\mathrm{a}, \mathrm{b}}$, Ana Luisa Marques ${ }^{\mathrm{a}, \mathrm{b}}$ \\ a Faculty of Engineering, University of Porto, 4200-465 Porto, Portugal \\ ${ }^{\mathrm{b}}$ Centre for Enterprise Systems Engineering, INESC TEC, 4200-465 Porto, Portugal
}

\section{A R T I C L E I N F O}

\section{Article history:}

Received 3 February 2016

Received in revised form 23 March 2016

Accepted 23 April 2016

Available online 25 May 2016

\section{Keywords:}

Hybrid process management

Knowledge based engineering

Collaborative engineering

Product design and development

Manufacturing planning

\begin{abstract}
A B S T R A C T
Today, manufacturing is moving towards customer-driven and knowledge-based proactive production. Shorter product life cycles lead to increased complexity in areas such as product and process design, factory deployment and production operations. To handle this complexity, new knowledge-based methods and technologies are needed to model, simulate, optimize and monitor manufacturing systems. Product lifecycle management research tends to focus on situations that are responsive to formal analysis and modelling. However, in several domains such as knowledge intensive collaborative environments, it's not possible to model processes using formal notations. Knowledge based and collaborative process management involves a combination of structured and non-structured processes. Structured processes management can be reduced to a set of fully-defined rules leading to high efficiency but also low flexibility, whereas the management of non-structured processes is not prone to a full formalization. A combination of both structured and unstructured management approaches is required in order to achieve a successful trade-off between efficiency, flexibility and controllability. We call a process as semi-structured when it contains both structured and non-structured sub-processes leading to a flexible and efficient hybrid approach. Large enterprise information systems, impose structured and predictable workflows, while knowledge based collaborative processes are unpredictable to some extent, involving high amount of human-decision. Moreover, large enterprise information systems are not able to manage the daily ad hoc communication inherent to the knowledge-based process itself. This paper introduces a set of concepts, methods and tools of an innovative Hybrid Process Management approach validated by a real world business case in the automotive industry.
\end{abstract}

(c) 2016 Elsevier Ltd. All rights reserved.

\section{Introduction}

Today, manufacturing management is being re-shaped by a shift from the mass production paradigm to a new on demand, personalised, customer-driven and knowledge-based proactive production paradigm. Shorter product life cycles, an increased number of product varieties, high performance processes and flexible machines and production systems result in an increased complexity in all domains from product design, process development, factory and production planning to factory operation. To face these challenges, companies are moving to intensive use of manufacturing knowledge in early phases of engineering and manufacturing activities in order to increase the efficiency of manufacturing systems. New value-added products, reassured and

\footnotetext{
* Corresponding author.

E-mail address: filipe.d.ferreira@inesctec.pt (F. Ferreira).
}

trusted planning of processes and adaption of factory structure are now critical factors for business success, which leads to the need of a continuous exchange of knowledge as well as improvements on the communication between the operation and the design and planning domains.

The current challenge in knowledge intensive collaborative environments is the integration of the product, process and factory worlds, in order to reduce the planning time and give reality to the synchronisation and alignment of products, processes and factories life cycles with the production operations (Tolio et al., 2010). Furthermore several critical aspects like the increasing complexity of product and production systems and the synchronised communication between the factory level domains (product design, process development, factory and production planning and factory operation) are other major challenges in the management of knowledge intensive collaborative environments. Reference models supporting planners and interdisciplinary teams can be used to overcome these challenges (Constantinescu, Hummel, \& Westkämper, 2006; 
Westkämper \& Hummel, 2006; Ferreira, Marques, Faria, \& Azevedo, 2016).

This is not a matter of technology, but how to fit the available technologies in the best way to capture the knowledge, to embed context into the knowledge, to use/re-use the knowledge in an intelligent way and to share the knowledge among all manufacturing stakeholders and to involve and motivate people during the entire product, process and factory lifecycle phases.

Currently, enterprise information systems, such as Product Lifecycle Management (PLM) platforms, are often large applications encompassing multiple functionalities that are expensive, difficult to use and hard to maintain (Moody, Gruen, Muller, Tang, \& Moran, 2006). It is also observed that in many cases existing information and communication technologies tools are not prone to manage effectively daily activities due to their lack of flexibility regarding dynamic (Kammer, Bolcer, Taylor, Hitomi, \& Bergman, 2000) and changeable environments and processes (Lu, Sadiq, \& Governatori, 2009; Mangan \& Sadiq, 2002). Large enterprise information systems impose structured and predictable workflows, whereas "real world" processes, in particular, those related with concept and design of new products and services are hardly predictable once they involve several human based decisions and collaboration (Hill, Yates, Jones, \& Kogan, 2006; Lu et al., 2009). Moreover, many times, large enterprise information systems are not able to manage communication and information together with the knowledge-based process itself (Mangan \& Sadiq, 2002).

Indeed, in the context of related engineer project activities, team members are forced to use office productivity tools such as spreadsheets and text editors as well as shared folders and internal email and phone to manage processes in largely unpredictable work environments (Hill et al., 2006) (Jørgensen, 2001). This is leading to a major shift in the Enterprise Information Systems (EIS) paradigm and to the development of cross linked and easy to use in order to support the product designers, process planners, and shop floor managers in their daily activities with a special focus on supporting collaboration in flexible work environments. Tools must be smooth, smart and fault tolerant in the interaction with the knowledge workers, and provide the integration of the shop floor level with engineering along the whole product life cycle (Hill et al., 2006; Brocke et al., 2010).

This paper presents a complete solution to support product lifecycle management in flexible work environments in the scope of industrial equipment engineering, planning, manufacturing, maintenance, improvement and decommission, including integrated work, information and communication management. The rest of the paper is organized as follows: section two presents the main phases considered in the research methodology. Then, in section three we highlight the theoretical issues related to this research work. In section four, we briefly describe the considered business case and we explore the main processes, starting with the diagnosis, followed by a short reference to the designed solution. The next section present the implementations issues as well as the validation process. Finally, overall conclusions are mentioned in Section 7.

\section{Research methodology}

The work presented in this paper has followed a research methodology that encompasses four main phases, as described hereafter:

(i) Background and Literature Review, where topics such as process lifecycle management and knowledge intensive collaborative environments, i.e., flexible work systems are explored. (ii) Business Case Presentation and Analysis, where the current practices of process and product concept, modelling, implementation, utilization, improvement and decommission, followed by a wide range of industrial equipment manufacturers were analysed and mapped using accurate techniques for business process analysis. Several workshops were conducted, in order to collect qualitative and quantitative data and relevant information, taking into account the expertise of all team members and experts. After analysing the as-is situation, current industrial challenges and issues and consequent improvement opportunities were identified, the to-be business processes were designed and validated by the industrial partners, leading to the design, specification and development of new suitable and accurate supporting methods and tools. Industrialists, technology providers and researchers did participate in this task, bringing their multi-disciplinary expertise to the project.

(iii) Solution Design and Implementation: where a complete solution, founded on collaborative platforms was specified and designed taking into account issues, challenges and potential improvements identified in previous phases. This includes the functional and technical specification. Having specified the complete solution, a comprehensive software package was developed using the most advanced technologies aligned to stakeholder's needs and constraints such as security, maintainability, usability and sustainability. Integration with legacy systems and openness to current advanced mobile technologies and cyber physical systems were considered and an open API towards full interoperability was developed as well.

(iv) Validation, where the solution was tested and validated by the end users in their daily work. In order to guarantee its sustainability, criteria for the solution evaluation were established and measured, paving the way for a successful exploitation and pointing out the strong points as well as aspects to be improved.

The next Sections are directly related to the four stages of the methodology.

\section{Foundations and research topics}

\subsection{Semi-structured processes}

Workflow management research tends to focus on situations that are prone to formal analysis and modelling. However, in several business areas, there are domains, such as knowledge intensive work environments and collaborative engineering environments (Moody et al., 2006; Faria, Silva, \& Marques, 2010; Faria \& Nóvoa, 2015), in which it is not possible to fully structure and model processes using formal notations (Kammer et al., 2000; Hill et al., 2006). The flow of so called semi-structured processes is not known a priori, and many times, only the main phases and baselines may be specified a priori (Lu et al., 2009; Mangan \& Sadiq, 2002). Efforts have been made to classify this kind of processes based on formal approaches, but the results achieved so far are limited (Paola Soto Rojas, Barros, de Azevedo, \& Batocchio, 2012).

The characteristics of a structured process include (Adams, Hofstede, Edmond, \& Van Der Aalst, 2006):

- The scope is totally defined and all the activities are known;

- It is possible to identify the initial state, a goal state, and all potential transitions;

- Activities and Transitions are computationally practicable. 


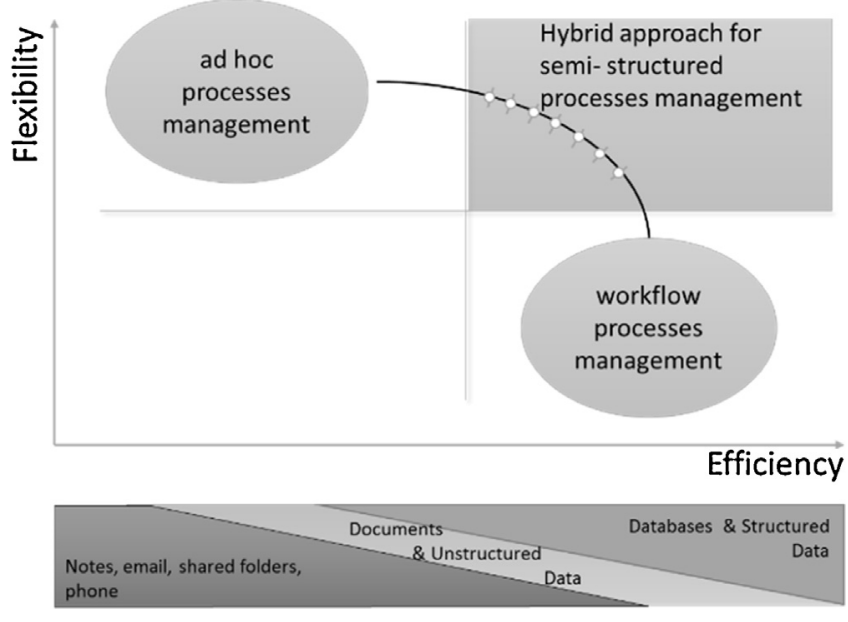

Fig. 1. Flexibility vs. Efficiency in Process Management.

Despite the apparent simplicity of the above characteristics, many companies try to implement workflow systems to manage non-structured processes with no success due to the fact that a formal definition of a semi-structured process is not possible. This happens because that there is no clear boundary and it is not easy to differentiate between what can be classified as structured and semi-structured (Rojas \& Azevedo, 2014; Swenson, 2000; Faria et al., 2010; Faria \& Nóvoa, 2015)

Many times, the low-efficiency concern and the lack of knowledge on the field lead business analysts from determining when a process fits for a fully automated workflow system or not. In fact, humans are better than computers for non-structured and fuzzy situations: e.g. case management (Shamsuzzoha, Ferreira, Azevedo, Faria, \& Helo, 2013; Almeida, Ferreira, Azevedo, \& Caldas, 2013). On the other hand, workflow systems tend to be better than humans for totally structured processes. However, many business processes fall in between the two extremes, as shown in Fig. 1. This leads to difficulties when companies have to decide if a process should fully or partially automated, or not automated at all (Ferreira, Shamsuzzoha, Azevedo, \& Helo, 2015; Shamsuzzoha, Ferreira, Sven, Helo, 2014; Azevedo, Faria, \& Ferreira, 2014) (Wiendahl, Wiendahl, Duffie, \& Brieke, 2007).

Since a non-structured process is not necessarily constrained by well-defined rules, it may have properties that differ significantly from those of a structured process. Some important implications of non-structured processes include (Azevedo \& Almeida, 2011; Carneiro, Almeida, Lopes Azevedo, Kankaanpaa, \& Shamsuzzoha, 2010; Kim, Chin, Kwon, \& Darin Ellis, 2009):

- Inputs may not be completely definable;

- A priori optimization is not definable since optimization implies the use of rules;

- Increased flexibility, since a non-structured process cannot be fully decomposed;

- There are fewer known constraints.

A semi-Structured process consists of both structured sub processes and non-structured sub processes, which interact in a known way. It is believed that many decision processes are semi-structured, and that this concept can help to understand human-automation decision systems.

In summary, decision making involve two types of processes: a structured process is a process that can be reduced to fully-defined rules leading to high efficiency but low flexibility (typical workflow management systems), while a non-structured process is not reducible to fully defined rules, leading to high flexibility but low efficiency and control (typical ad-hoc managed processes (Tolio et al., 2010)). A process is semi-structured when it contains both structured and non-structured sub processes thus requiring hybrid approach providing the right balance between efficiency, flexibility and controllability (Fig. 1) (Zelm, Kosanke, \& Vernadat, 1999; Doumeingts, 1984). This process distinction has many implications in process management systems design, including the allocation of processes to humans and automation (Kemppilä \& Mettänen, 2004; Weber, Reichert, \& Rinderle-Ma, 2008).

\subsection{Reference models}

There are several methodologies for product design. They enable a systematic engineering of products. The most important documents in the field of methodical product design is the guideline (VDI2221 1993) provided by the Association of German Engineers (VDI). Most standard works of engineering design refer to this guideline (Grote \& Feldhusen, 2007; Pahl, Beitz, \& Wallace, 2007). Other guidelines refine the design process introduced in the before mentioned guideline from different points of view. For instance, the (VDI 2222 1997) refines the development of principle solutions and (VDI 2225 1997) focuses on the financial aspect of methodical engineering of products. Design processes, which claim to have a model-based approach, are rare.

Eversheim (Eversheim, Rozenfeld, Bochtler, \& Graessler, 1995) introduced a reference model for concurrent engineering to provide a methodology for an integrated design and process planning. The "Münchner Vorgehensmodell" (MVM) pursues an object oriented structure for the product design process. State-of-the-art reference models for Process Development and Factory Planning provide defined, structured and standardised workflows for different factory and process planning activities to overcome the current challenges in Manufacturing Engineering (Constantinescu et al., 2006; Westkämper \& Hummel, 2006).

The predefined standardised planning activities improve the communication between planning partners, interdisciplinary teams or stakeholders, who participate in different phases of a factory planning activity (Constantinescu et al., 2006; Westkämper \& Hummel, 2006). The first factory reference models were proposed as factory structure reference models. These reference models are targeted to a specific industrial sector or they are very generic and describe the structure of a factory without taking its life cycle or processes into account. Today's reference models for Process Development and Factory Planning provide a various level of detail for each planning phase and support different phases of the factory life cycle. Kettner, Aggteleky, Grundig and Wiendahl concentrate on the factory planning (investment-,building-, layout-, logistics planning and ramp-up) without considering the manufacturing execution planning and the dismantling of the factory (Wiendahl et al., 2007).

A more holistic view on the factory planning life cycle is provided by the VDI and Westkämper. There the factory life cycle phase "manufacturing execution" is additionally taken into account. However, the dismantling is not considered in those approaches. Helbing provides a factory and process planning reference model, which concentrates on the factory planning phases up to manufacturing execution in a highly detailed way. An innovative point in Helbing's approach is that he also takes the relations and interdependencies between the planning phases into account. The approach of Schenk, Wirth and Müller concentrates on the whole factory life cycle including manufacturing execution and the dismantling of the factory, also the information flow in the manufacturing execution phase is considered briefly (Schenk, Wirth, \& Müller, 2010). The VFF reference model for Factory and Process Planning is a generic, modular, open and extensible reference model taking into account the factory planning phases from investment planning to ramp-up. Every planning phase is described 
through detailed, structured and standardised planning activities. The information flow between the planning phases is also considered (VFF NMP-4). The methodology and reference models for Product and Factory Lifecycle Management are implemented in several existing commercial software applications, such as SIEMENS Teamcenter PLM, PTC WindChill; Dassault Enovia.

The CIRP working group SPECIES (2005) highlighted how critical the integration and evolution of products, processes and production systems along their life cycles is. Tolio et al. (2010) addressed this evolution problem both from the industrial and academic point of view, by presenting industrial use cases and extensively analysing the scientific literature, respectively. Moreover, the authors presented a reference model to study the integration between products, process and production system in terms of requirements to face a specific industrial problem, constraints imposed by the internal and external Factory Environment, and capabilities offered by methodologies and tools. Finally, Tolio et al. proposed a list of future research priorities to be addressed: need of technical standards for evolving information related to product, process, production systems; development of co-evolutionary Design-for-X methodologies; new production system architectures to support the changes in products and processes; reconfigurable process plans.

Like stated, the state-of-the-art reference models aim mainly at decreasing the complexity of the planning activity and modelling and managing all the necessary information and communication flows. However, these reference models are not able to connect the different planning life cycles of the product, the process and the factory in a knowledge based approach. Another crucial aspect is the knowledge-driven communication within the Factory Level. This is not supported by the existing reference models. Finally, there is a lack of knowledge-driven supporting ICT technologies to enable an effective and efficient communication and data exchange within the product design, process development, factory and production planning and factory operation

\subsection{ICT for knowledge intensive knowledge engineering}

Current Product Lifecycle Management systems provide an integration of product data with the use of conventional database approaches. The ERP systems are less product-focused and emphasise more on the integration of the business processes. In the last years two modules namely the CATIA V5 Knowledge aware and the Siemens Teamcenter have emerged and are mainly in support of product knowledge management. Both of the modules use the concept of the so-called templates or archetypes that focus on reusing parameterised, modular part designs. Both the EPR and the PDM/PLM systems are still considered weak in knowledge management, especially for the process related knowledge management; while the integration of knowledge based tools into PDM, such as the Distributed Open Intelligent PDM system are few (Kim et al., 2009; Jiang, Peng, \& Liu, 2010). Another similar approach that may act complementarily to the existing PLM/PDM systems and may reduce time and cost of the early design phases has been proposed in Chryssolouris, Mourtzis, Papakostas, Papachatzakis, and Xeromeritis (2008a). In particular, this work introduces a new theoretical framework for analysing and classifying knowledge, related to existing assembly configuration, in terms of manufacturing attributes such as time, cost and flexibility. Product cost estimation during the early design phase of the product development is a process of great significance since it facilitates the cost control and influences positively the enterprise. A great obstacle of estimating the product cost, during its design phase, is the lack of information. Knowledge based systems mostly following case based reasoning approaches, attempt to overcome this problem and provide a first estimation of the product cost. The DATUM project (Design Analysis Tool for Unit-cost Modeling (Kim et al., 2009)) aimed at the development of a knowledge based system, capable of estimating the cost of an aircraft's engine and its subcomponents and generating a process plan for the manufacturing of the engine. A similar application to the automotive industry has been developed in the context of the MyCar project (Makris et al., 2010). In particular, a knowledge based system for subassembly cost estimation has been implemented, following a hybrid methodology utilising case based reasoning and regression analysis (Mourtzis, Efthymiou, \& Papakostas, 2011).

In today's industrial world, a number of tools are used, for controlling and monitoring production lines in various areas. SAP's PLM v7.0 is considered to be one of the most stable and mature platforms available for Product Life cycle Management, integrating the business (ERP) information with the engineering information in a common platform. The SAP PLM enables planning and decision making so as to connect product plans with corporate growth strategies. Through the Product development and collaboration feature, people that work in different sectors of a company can share information such as project plans, technical drawings, documentation etc. In manufacturing the tool allows integrated product and process engineering by collecting all the data for the product's life cycle in one integrated model, particularly for products with many variants and repetitive manufacturing processes.

A more detailed review of commercial PLMs follows. A wellknown system for the manufacturing process management is Dassault Systèmes' DELMIA. By using DELMIA's Process Engineer module, engineers are able to recognise process risks or re-use proven processes through the comprehensive treatment of the relationships between product, process and manufacturing resource data. DELMIA uses a PPR Hub to map the planning content and thus allows all of its users to work with the same up-to-date data. Dassault Systèmes' collaborative life cycle management tool called ENOVIA is used for product design oriented decision making by providing collaborative product reviewing and simulation features when used with other products from the company such as CATIA, DELMIA etc. In 2010 Dassault Systèmes introduced 3DLive which is an application that introduced a 3D paradigm for on-line collaborative intelligence, leveraging a company's 3D and PLM data.

Siemens Tecnomatix is another popular PLM software among European industries including Aerospace and Defence, High tech \& Electronics and Automotive. Tecnomatix is mainly used as a tool for optimising and commissioning of robotics and automation, manual workplace configuration and placement of equipment and material flow. It includes a number of simulation and validation tools for manufacturing processes. The Teamcenter Manufacturing Process Management (manufacturing processes management tool of Tecnomatix) provides parallel execution and control between engineering and manufacturing teams and has architecture built with open technologies to cooperate with existing IT software. Oracle's Agile Product Life cycle Management for Process which includes the Agile Product Data Management allows data distribution between ERP systems and PLM tools through external integration software.

Through their Application Integration Architecture (AIA) prebuilt content, templates and methodology for orchestrating agile user-centric business processes across enterprise applications can be utilised. That architecture enables Oracle and non-Oracle applications to work together since it is built on Fusion Middleware's Service-Oriented Architecture (SOA) and BPM framework. Most commercial systems are still not considered mature enough when it comes to the cooperation of teams from different companies who use different applications for the optimisation of the manufacturing process, addressing the market's needs in real time. Software architectures and frameworks supporting fast setup of knowledge management systems within a whole manufacturing system, would make a large advantage (Chryssolouris, Mourtzis, 
Papakostas, Papachatzakis, \& Xeromeritis, 2008b). These tools represent knowledge about the manufacturing processes only partially. They don't support the systematic organisation of past experience and knowledge in a way that it can be easily reused in future projects. The engineers often have to rely upon their experience and search for past relevant solutions in their companies' databases. The way knowledge is perceived by each engineer and each company is usually different and therefore it cannot be used in a collaborative manner by different engineering teams, who, by the way, may be using different platforms or applications.

The main weaknesses of existing approaches, systems and models that attempt to address knowledge based work management can be summarised in the following.

- Focusing mainly on the product design knowledge.

- Rules, equations and constraints are only available for product design.

- Process and resources related knowledge is not addressed.

- It does not offer the capabilities of semantic technology.

- Lack of defining, retrieving and storing best practices.

- Lack of generic similarity measurements.

- Lack of associating, product, processes and resources with Key Performance Indicators.

\section{Business case presentation and analysis}

The business case considered in the context of this research project addresses a plant in automotive industry that produces several car models in a single assembly line. It presents a very highly dynamic and flexible behaviour, achieved through qualified and motivated people, continuous improvement and innovation.

In this automotive plant, a specific Business Unity (BU), dedicated to dies construction, together with other four tool shops, supports die constructions as a core technical business worldwide. With a workforce around 230 employees and equipped with modern milling machines and try-out presses, this BU is able to follow-up several die-sets projects from analysis phase till the process validation phase.

Every time a new car model is to be launched, a set of stamping dies have to be designed, produced and validated. This set of dies is managed by a dedicated team that has to handle a huge amount of information flowing thru the different stakeholders along the full project life cycle. Having the right information at right moment, to take fast and well based decisions is a main challenge managers have to face.

The die-set development process was split into three main stages: planning, machining and evaluation stages. In fact, the development of each die-set may be shared by the OEM and a supplier, or managed entirely by the OEM or a supplier. Here, the decoupling point depends on the level of expertise of the buyer to deploy and control this process.

The planning is one of the most critical stage of the die-set (DS) development process, since the outcome of the each one of the activities of the process - Team Definition, Simulation \& Feasibility Study, Capacity \& Resources Allocation, Die Concept \& Process Simulation and Components Design - may affect the performance of the overall process execution.

The following figure shows the main stages of the die-set development process (Fig. 2).

Starting from the project's team definition, each technician is responsible for a series of die-sets, distributed to a small number of suppliers (one or two maximum in order to enhance the buyer-suppliers relationship). Then it is necessary to execute the right simulations and feasibility tests, in order to understand if the technical specifications of each die are correct from a product and manufacturing point of view. After validation of the technical specification for each die-set, it is important to understand if the plant, where the die-set is going to be used, has the resources necessary to apply the die-sets designed. In other words, if the facilities have enough space to store the die-sets, during the "homeline" try out and production, as well as understand if there is any available press capable to apply, for instance, the forces and torque necessary. Known and validated the die-sets, as well as the necessary resources, it is possible to build a $3 \mathrm{D}$ model of each die-set, as well as plan the die-set construction, in terms of budget, time and quality. Here it becomes critical to specify the quality standards to be validated at the end of the process execution.

The following stage, the machining, is where the supplier has to transform the die-set 3D model into a final and usable die-set, capable to produce the parts as specified by the product owner.

The final stage is focused on the evaluation and improvement of the die-set model built, towards the successful production of the idealized parts. Here, both company requirements and quality standards defined during the planning stage must be taken into account. Thus, as first action, technicians must build some prototype parts in order to validate if the dies are fulfilling the expected quality standards. After all product requirements being validated the manufacturing process is tested thought a pre-series evaluation. If minor problems are identified, then correction action must be taken in buyer's house, following an iterative approach.

After analysing the as-is processes, it was possible to assert that the continuous updates on each die-set (DS) status were consuming a considerable amount of time and resources making the decision making process more reactive instead of the desired pro-active approach. It was also possible to see that the information is spread by numerous departments and specialists and can be in paper format, PDF/Word format or even plain text in e-mails. This approach in the data gathering represents a severe concern since it can be the cause of wrong or slow decisions due to misinformation in a process that is very time dependent.

A practical example is the one where two tasks revealing important updates in the process are made. If the process runs perfectly and everything is considered correct in the first execution, the information along this process can be single set of documents per task: Otherwise, when the process steps through multiple interactions to reach a valid result, multiple versions of the documents will be generated and archived.

Therefore, the process for a single die-set may generate an high amount of data and documents that need to be searched, organized, reported, kept, tracked and stored for future projects posing serious requirements regarding the reaction times and reliability of information.

In fact, we know that an initial plan is expected for the process (Fig. 3). However, based on the nature of the case, every instance may flow a different flow, as some task as to step over several interactions or executed in a different than the one initially planned (Fig. 4).

The current state of the process weaknesses can be summarised and identified in the following list:

- Human intensive processes with high level of improvement and feedback loops;

- Transversal and hierarchical projects involving several departments and objectives within the organization;

- Management based on individual trust;

- Low capacity for knowledge capture and reuse;

- The number of people involved and information's storage formats are incompatible with a pro-active approach;

- Ad-hoc communication flow; 


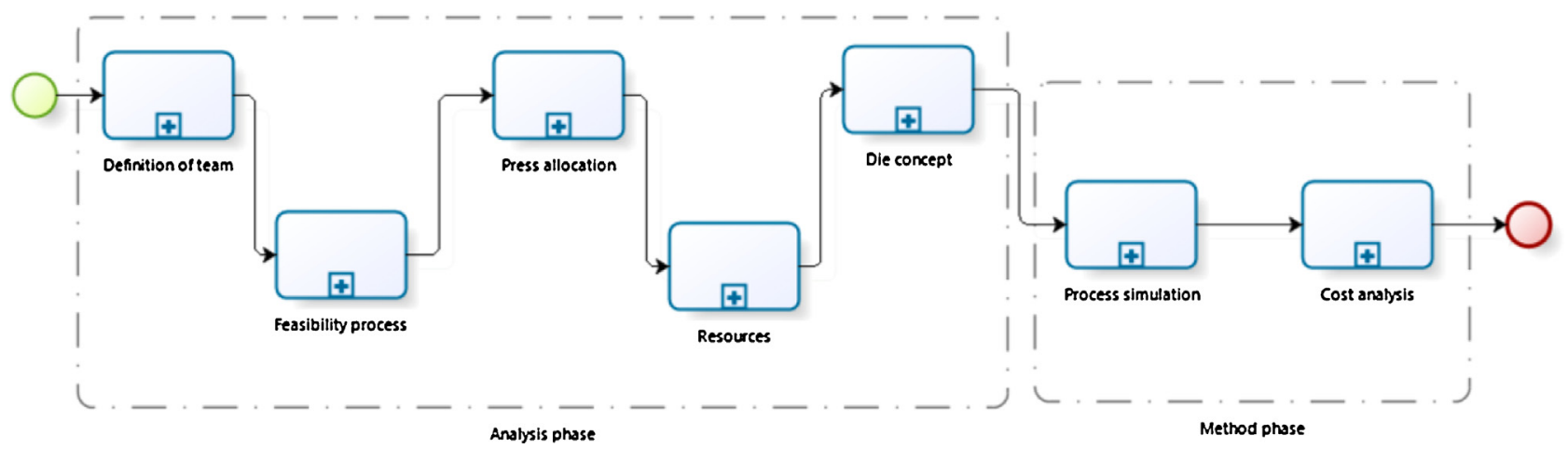

Fig. 2. Main stages of the die-set development process.

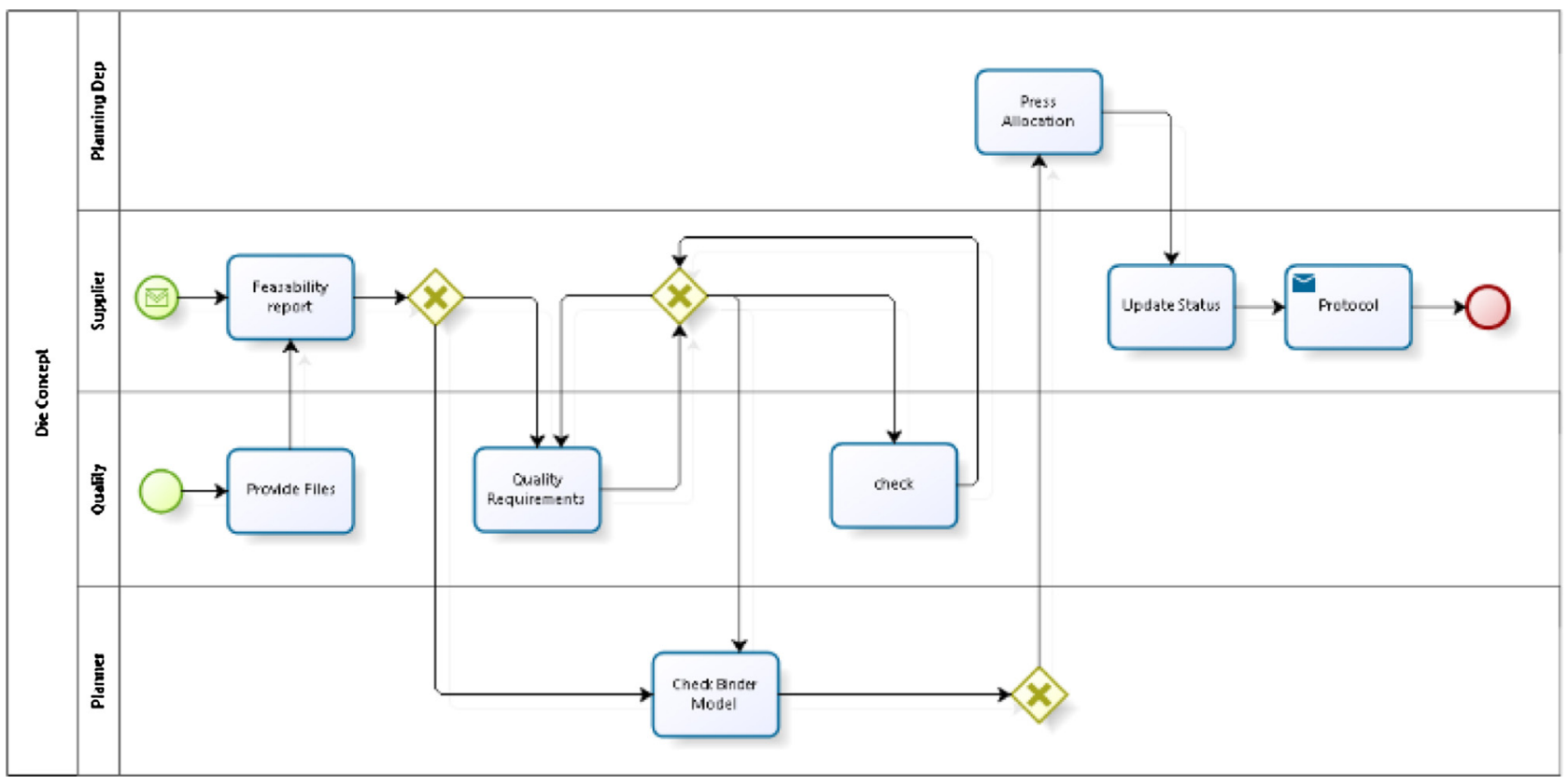

Fig. 3. Expected Process Flow.

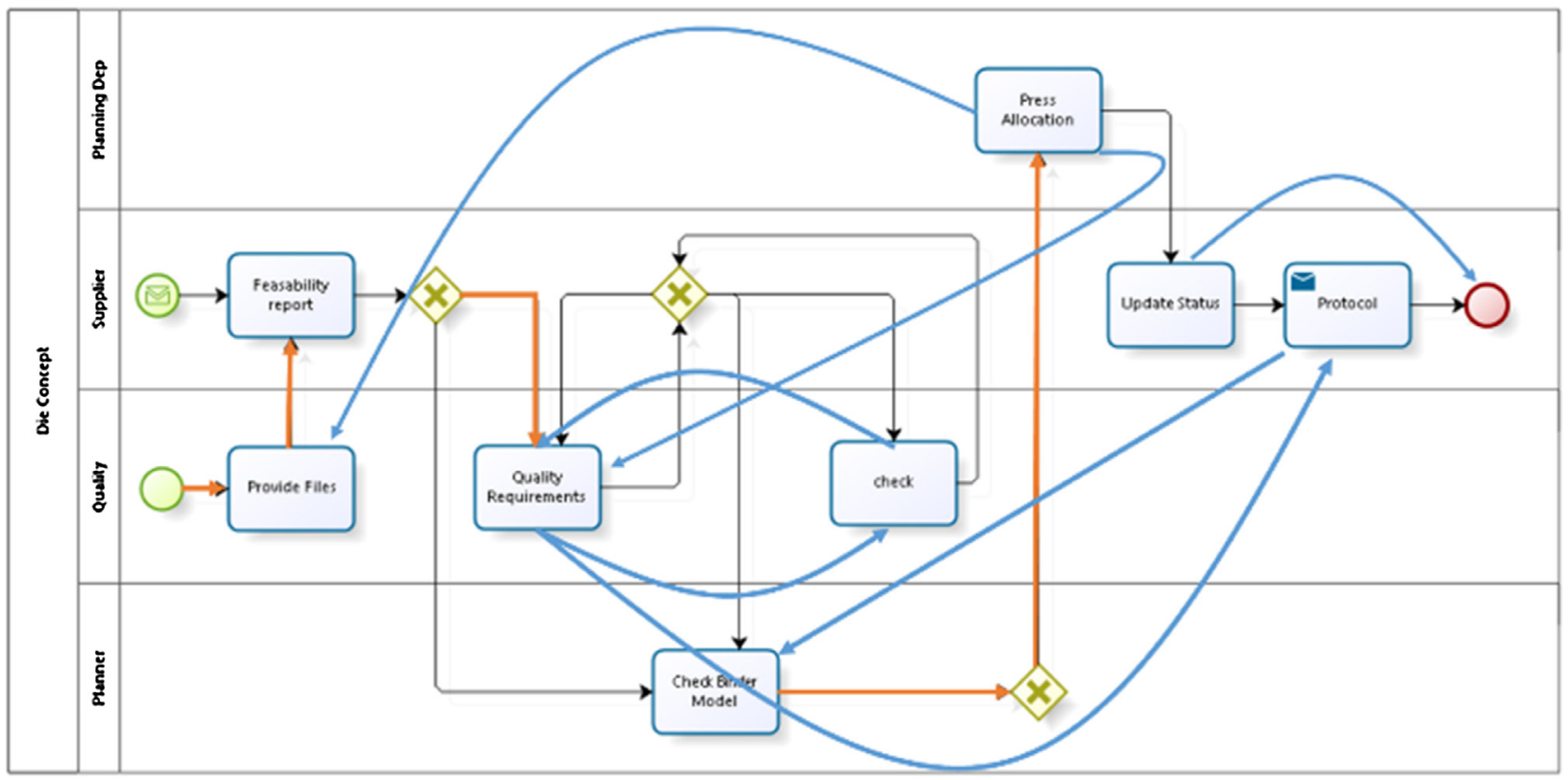

Fig. 4. Expected vs. Real Process Flow. 


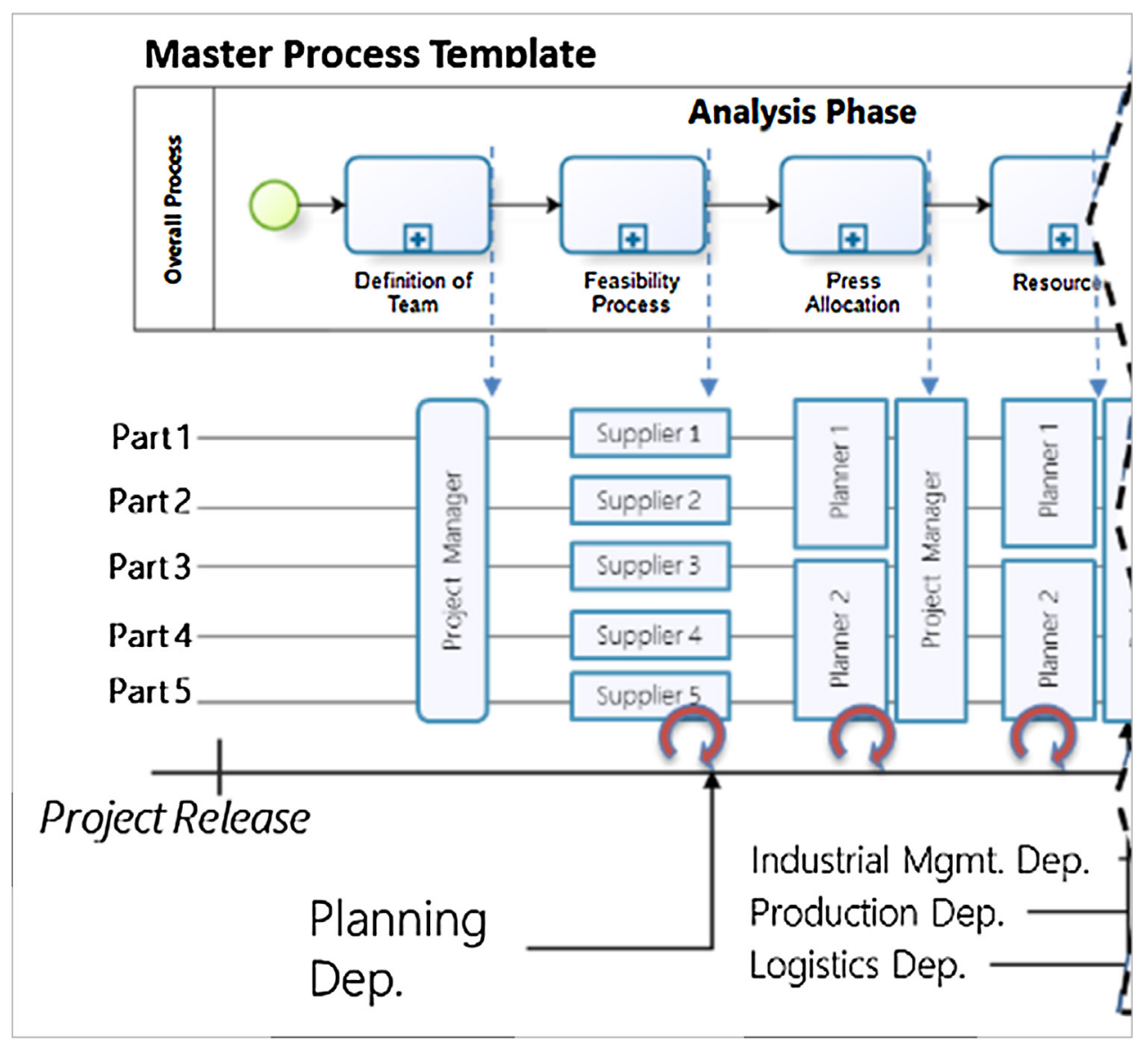

Fig. 5. Main interaction inside the collaborative process.

- The reliability of the data is compromised because of the communication methods and data formats;

- The current storage method for data makes it difficult to gain access to it;

- Time dependent processes that do not allow on-time/online monitoring;

- Lack of standardized knowledge based databases fed by past experience and personnel knowledge;

- Processes dependent on individual expertise;

- Processes do not incorporate a best practices repository or past experiences;

- High risk of misinformation.

Another important characteristic of this kind of processes stays on the fact that the cardinality of the tasks changes along the life cycle. As we can see in Fig. 5, activities may be tackled together or separately, depending on its nature and/or corresponding actor(s). For instance, the definition of team is done once for all process instances at the master process level, while feasibility studies are realized per supplier and the press allocation depends on the number of parts that each planner is responsible for.

Having analysed the as-is state in detail by considering the BPMN process mapping it was possible to understand that many of the weaknesses of the existing management system that were identified could be eliminated or, at least, minimized by a pro-active management approach for the die-set development process, as it will be discussed in the next section.

Given this scenario, it is clear that managing a die-set program for a new car model or variant requires a holistic view of managing several hundreds of individual instances depending each one on the others. When some decisions are being made individually it can affect other running projects. For example a decision in the development of one DS can have indirect consequences in other running DS development projects. Additionally, it requires managing several suppliers, stakeholders and documents that are being continuously updated into new versions due to improvements or unpredictable changes in the product development. The challenge is how to manage effectively the product development process when the information collected is dynamic, comes from multiple sources (stakeholders and software tools) and has dependences.

Our analysis of the die-set development process showed that its management makes use of intensive human knowledge (only highly skilled resources based on experience and expertise are chosen). It has a step-by-step methodology with a high level of improvements and feedback loops, through the lifecycle of the product development, demanding a very flexible and real time monitoring process.

Moreover, the complexity of the die-set development process increases because each step can be performed by a different expert team with different goals. The existing interdependencies must be taken into account to avoid lack of consistency. Additionally, there is a huge amount of information and communication flow being managed.

The need to control this flexibility due to product development time constrains led to the development of the Hybrid Process Manager (HPM) application that is helping to control the several steps and sub-steps, tasks and activities of the process in terms of time, information and communication flow. Moreover, information generated along the different activities of the process life cycle, is classified and achieved according to its relevance for process execution, reducing the time and effort need to undertake decisions. 


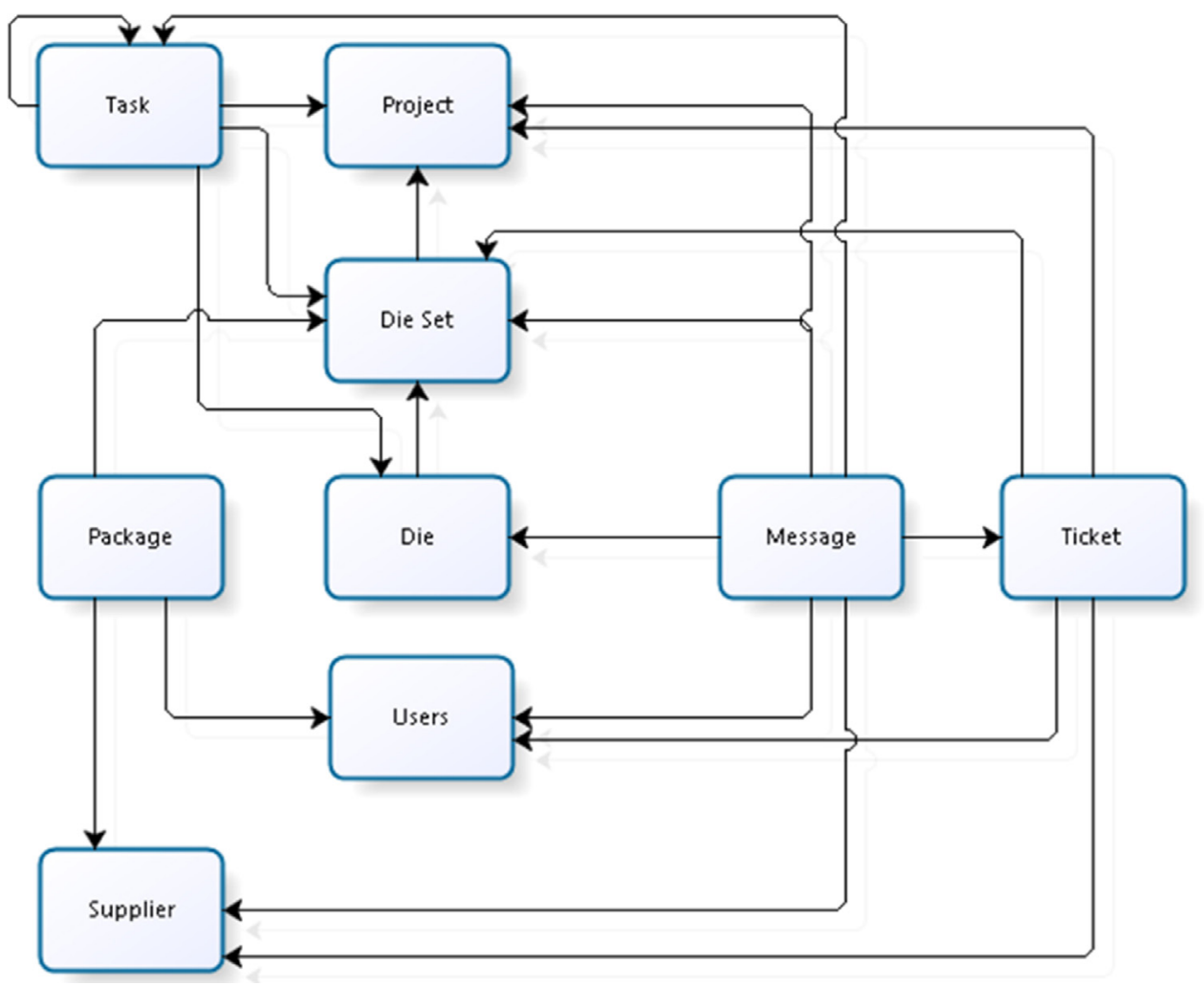

Fig. 6. Solution Domain Model.

The following figure shows the main entities of the domain being analysed (Fig. 6).

Communication inside the concurrent die projects was employing traditional paper or e-mail messages, which were easily forgotten, lost or ignored when the work environment becomes overloaded. The communication tools that were developed allow connecting all stakeholders and interdisciplinary teams that are involved in the product development, guaranteeing real-time information regarding updated documents, problems and other relevant issues (Tickets), thus saving time and improving the decision making processes.

As stated before, the product development process of building a new die, requires a lot of expertise, experience and knowledge that are valuable on solving problems and which were not captured, stored or re-used. The knowledge reuse process will be made through ticketing functionalities where the user can document in detail the problem of the part being developed, list of actions, method, solution, and verification and action plan. This information can be re-used when needed through a database with a problemsolution-result repository.

The product development process, as stated before, is very complex and requires the management of a high quantity of tasks with their problems and constrains. In order to keep track on the status of the tasks it will be monitored by an application which will allow the user to identify if a task has a delay.

Traditional project management is mostly seen as a monocausal and non-dynamic work system with a linear structure that is unsuitable to solve the above challenges. The flexibility desired due to the dynamic system of product development requires a new approach that will allow to breakdown the communication and collaboration barriers between the product-process-factoryproduction levels. The adoption of the developed tool supports the company in facing this challenge and enables a faster and a more efficient product development process.

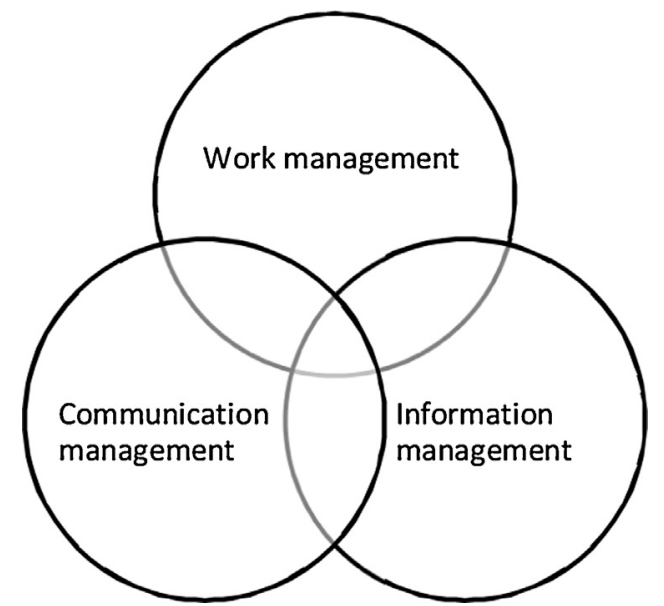

Fig. 7. Main functionalities of the hybrid process management application Solution Design and Implementation.

For example, in case here considered, when a new car project starts, the top management defines only some milestones that are controlled in an automatic way. However, the work that needs to be done between each milestone cannot be automated once it relies on human intensive knowledge and decision tasks, even if the final results are known. The combination of these structured and unstructured activities are equally important in terms of leading the project to its success (Sharp \& McDermott, 2001; van der Aalst, 2004; Andersson, Bider, \& Perjons, 2005).

In order implement the hybrid process management approach a computer application was developed encompassing three main groups of functionalities (Fig. 7): work management, information management and communication management as it will be described in the next section. 


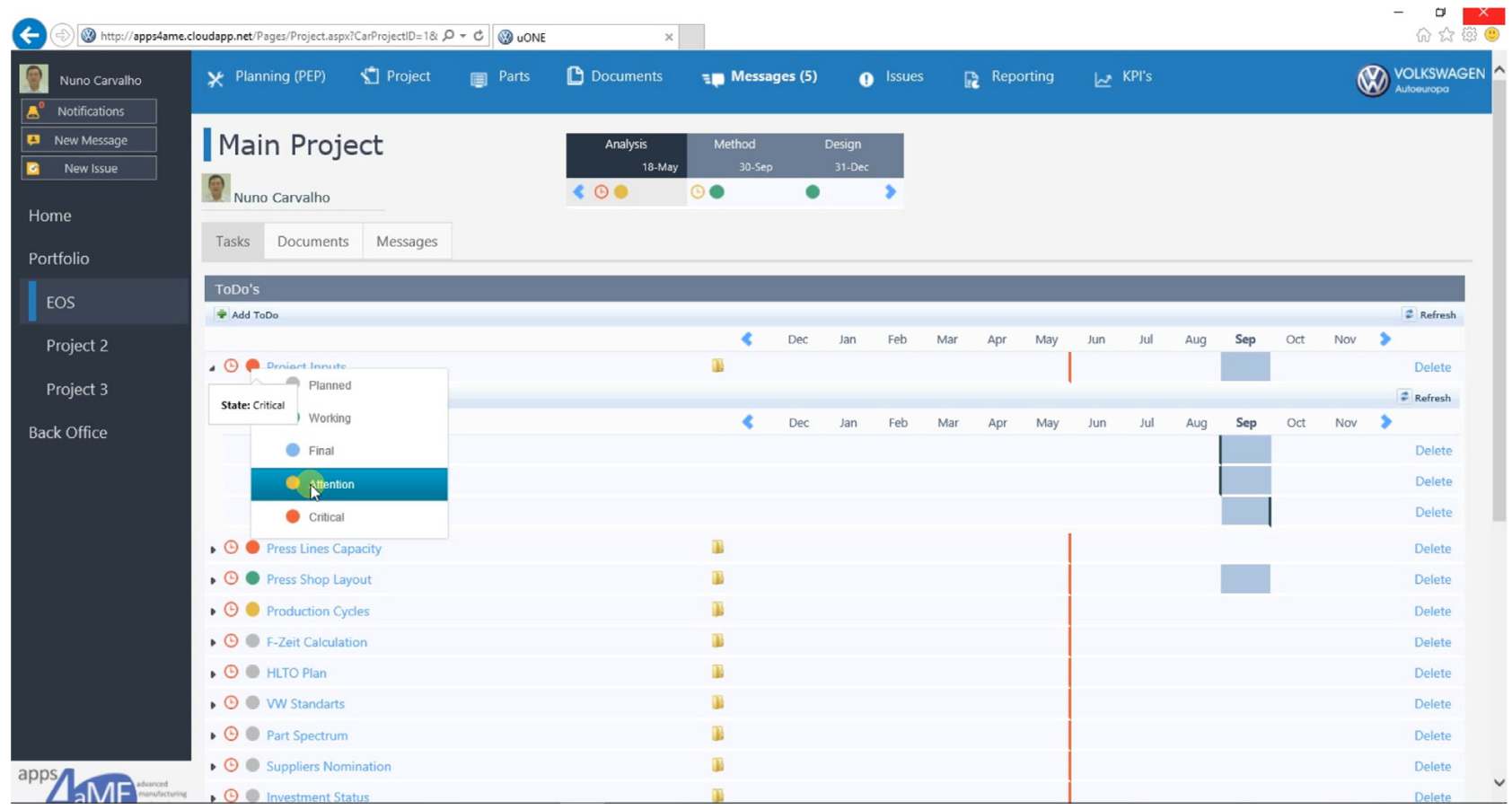

Fig. 8. Dashboard for holistic view of project status.

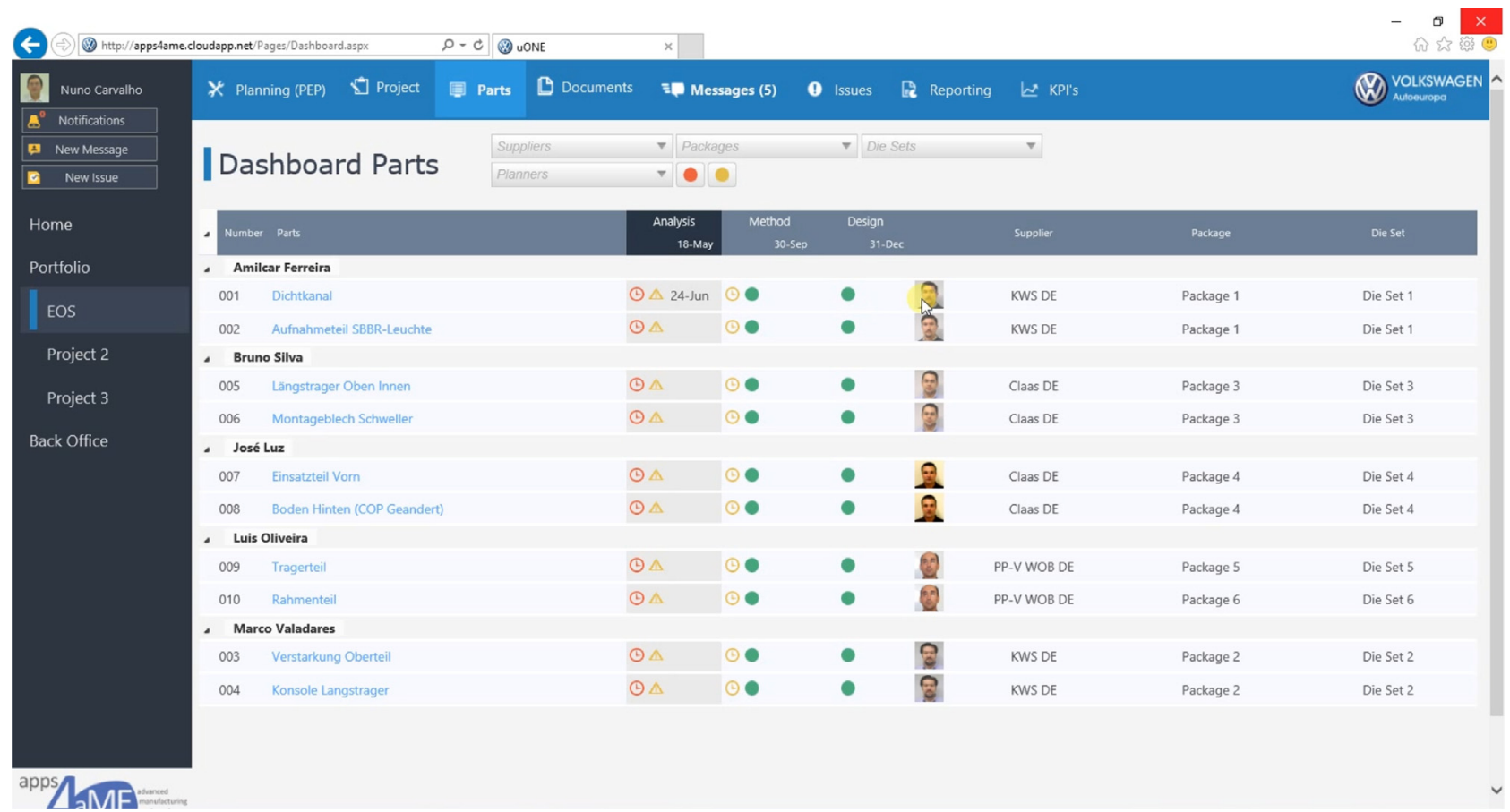

Fig. 9. Real time monitoring and control of the ongoing work activities.

The aim of the proposed solution is to facilitate the flow of information among partners, making it more reliable and actual, allowing a closer control and fast reaction. Working in cooperation with other departments or external partners, track the flow path, schedule, define milestones, handle project changes, evaluate risks and define actions, as well as control costs and capacities along the project development.

In order to successfully accomplish this mission, for each project this department need to collect and manage huge amount of information and knowledge, coming from inside and outside of the factory. Indeed, managing all this collaborative process and its information not only is intensively time consuming, slowing down decision-making process, but also hinders project reliability, increasing its uncertainty.

Specifically, the aim of the solution is to manage the product development process. Currently these actions have been done manually using numerous physical, electronic files and calls. Therefore all the information needed and used in the process is spread around several departments, reducing the reliability of the entire process to a minimum. To solve this, a new approach and solution is needed. 
HPM solution addresses the main challenges that are typical in this kind of semi-structured and knowledge intensive collaborative environments by implementing the following functionalities.

- Dashboard for holistic view of project status (Fig. 8);

- Real time monitoring and control of the ongoing work activities (Fig. 9);

- Totally integrated knowledge and documents management (Fig. 10);

- Technical integration with Windows and office tools, which are widely used by project teams (Fig. 12);

- Integrated communication/messaging along the process activities in the scope of each project/phase/to-do, eliminating the internal and project related email (Fig. 13);

- Problem solving support, including tickets management integrated with all entities (Fig. 14).
Table 1

Savings after HPM introduction.

\begin{tabular}{lllll}
\hline KPI Acronym & Units & AS-IS Result & Actual Result & Savings (\%) \\
\hline TACD & minutes & 30 & 5 & $83,0 \%$ \\
ORLT & hours & 3 & 0.5 & $83,0 \%$ \\
ORR & persons & 9 & 2 & $77,8 \%$ \\
RTCS & hours & 20 & 5 & $75,0 \%$ \\
PLT & months & 4 & 3.5 & $12,5 \%$ \\
PSV & $\%$ & 10 & 5 & $50,0 \%$ \\
\hline
\end{tabular}

\section{Validation}

During the process analysis and re-definition, a set of Key Performance Indicators (KPIs) was defined in order to measure the impact of the solution. Thus, for the successful implementation of the solution, the following KPIs were defined:

\section{$\frac{\Sigma(\text { ReportTime }- \text { requestTime })}{\text { sreports }}$}

\begin{tabular}{|c|c|c|}
\hline KPI name & Description & Formula \\
\hline ORT - Overall Report Lead Time & $\begin{array}{l}\text { Required time necessary to create an overall report } \\
\text { in hours }\end{array}$ & $\frac{\Sigma(\text { ReportTime }- \text { requestTime })}{\text { Ereports }}$ \\
\hline ORR - Overall Report Resources & $\begin{array}{l}\text { Required resources necessary to create an overall } \\
\text { report in persons }\end{array}$ & $\frac{\Sigma(\text { numberOfResources })}{\text { Ereports }}$ \\
\hline RTCS- Reaction Time on Critical Status & $\begin{array}{l}\text { measures the mean elapsed time between the } \\
\text { problems raise moment till its closing, when } \\
\text { they're solved }\end{array}$ & $\frac{\Sigma(\text { issueSolvedTime }- \text { issueRaisedTime })}{\text { Eissues }}$ \\
\hline PLT - Phase Lead Time & $\begin{array}{l}\text { The Mean time between the start of a project type } \\
\text { phase and the effective closing of that phase }\end{array}$ & $\frac{\Sigma(\text { EndPhaseTime }- \text { StarPhaseTime })}{\Sigma \text { phaseInstances }}$ \\
\hline PSV - Project Schedule Variance & $\begin{array}{l}\text { The variance between the project schedule and its } \\
\text { real execution time }\end{array}$ & $\frac{\Sigma(\text { RealEndPhaseTime }- \text { RealStarPhaseTime })}{\Sigma(\text { EstimatedEndPhaseTime }- \text { EstimatedStarPhaseTime })}$ \\
\hline
\end{tabular}

The process manager solution relies on an ASP.NET web application and taking advantage of Microsoft SharePoint foundation services, as depicted in the global architecture shown in Fig. 11. The application runs on Microsoft Windows Server on top of Microsoft SharePoint Foundation Server and its data model is implemented in SQL Server RDBM System. LINQ-TO-SQL is used to enhance the connection between server side C\# programming and database. Several libraries are used in order to integrate the application with native windows functionalities as well as Microsoft Office tools, which are widely used by knowledge intensive workers. The process manager UI is a totally web-based HTML5 and JavaScript technologies enabled. Several control libraries such as Telerik for AJAX.net and HighchartsJS were also employed in order to have a rich and high usable and flexible interface.

During the requirements elicitation process, it was clear that all stakeholders were using Microsoft productivity tools in their daily work. Thus, it became clear that a seamlessly integration with Microsoft productivity tools such as Windows Explorer and Outlook was critical.

Giving this context, is was decided to develop the application on top of .NET and SharePoint foundation frameworks in order to take advantage of its functionalities. Thus, the eApp is designed to run on windows server IIS using Microsoft SQL server and SharePoint Foundation services. Nevertheless, a Windows Communication Foundation (WCF) RESTful API was developed in order to have an integration endpoint with any kind of application such as java EE, android, iOS and others. Moreover, MVC Frameworks such as AngularJS can be employed to develop customized GUIs for specific devices like smartphones or tablets. Several required services and respective endpoints for data interoperability were developed using WCF RESTful web services. Representational State Transfer (REST) and JavaScript Object Notation (JSON) technologies were chosen due to its simplicity and proven effectiveness.
The solution was evaluated in real engineering environment inside the company, by the stamping planning team, which involves eight planners and a manager for each project. During this evaluation phase, a specific project has been used to test and verify the functionalities implemented. Each stakeholder has a specific credential to access, test and validate the functionalities, giving feedback for continuous improvement.

At the moment, by using a comprehensive Performance Measurement Engine, it was possible to measure and calculate the KPIs previously defined and compare the results, lead to the savings that are presented in the following table (Table 1 ).

\section{Conclusions and further developments}

The introduction of the solution developed in the knowledge intensive collaborative environment prove to be very effective and efficient, leading to good results in terms of savings. The introduction of the solution made possible that managers avoid asking for reports and a lot of time and paperwork is now saved. The solution allowed stakeholders to concentrate in important issues improving products and processes avoiding non-value added efforts and time on collateral activities. Other advantage is the data collection built in the solution storing historic and experience retrieval modules, allow access to expertise, knowledge and best practices collected from previous activities and available to incorporate in future as a factor of knowledge sustainability. The comprehensive dashboard allows the real time report of the process status, leading to savings in reporting time and resources. Due to integrated documentation and information management, engineering project's team members have now instant access to the right information at the right place and in the right moment, leading to a reduction of time to access critical data. The communication and issues tracking functionalities, allows key players to participate more actively in process management and improvement, thus enforcing team spirit. 


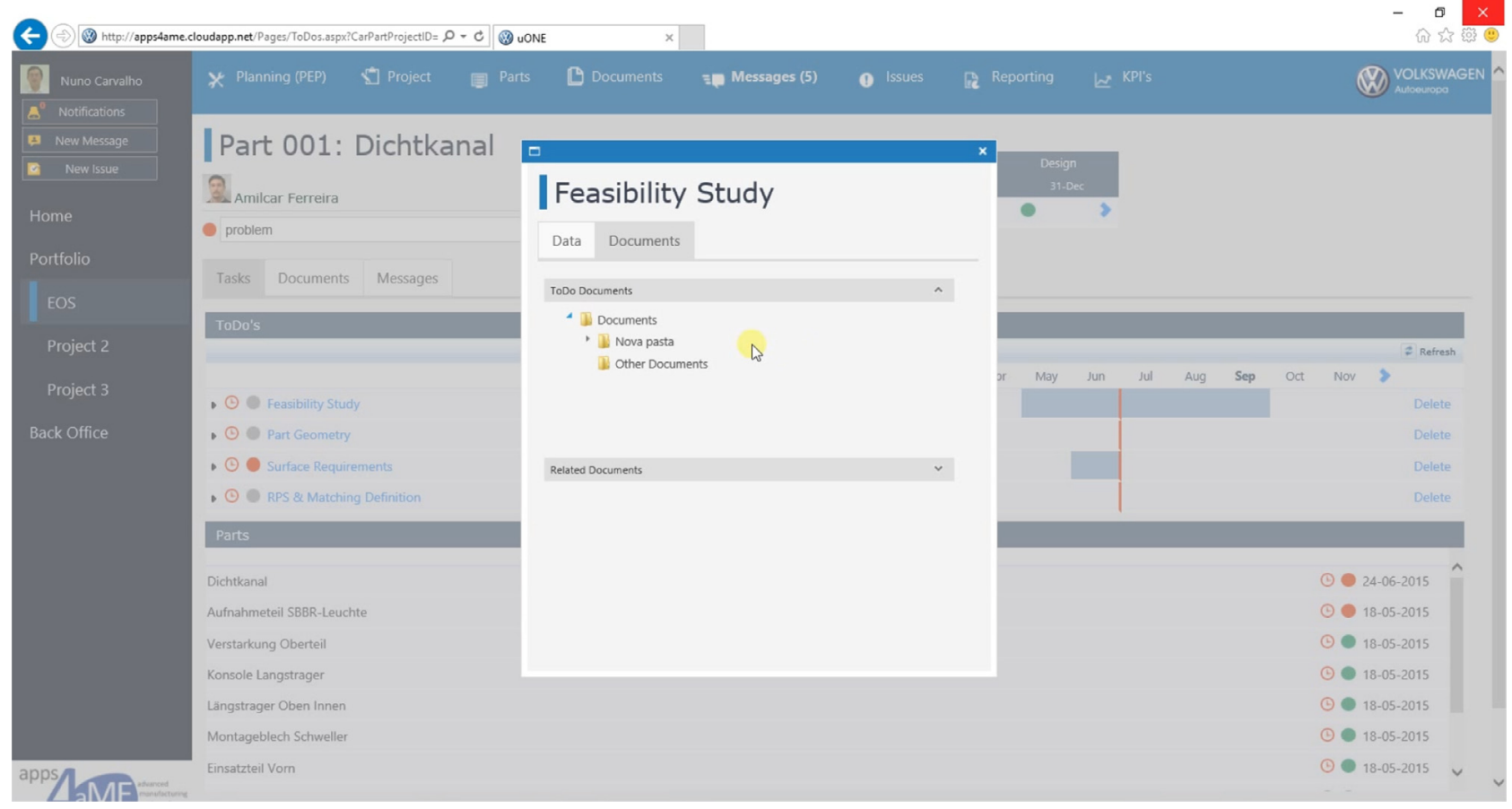

Fig. 10. Totally integrated knowledge and documents managemen.

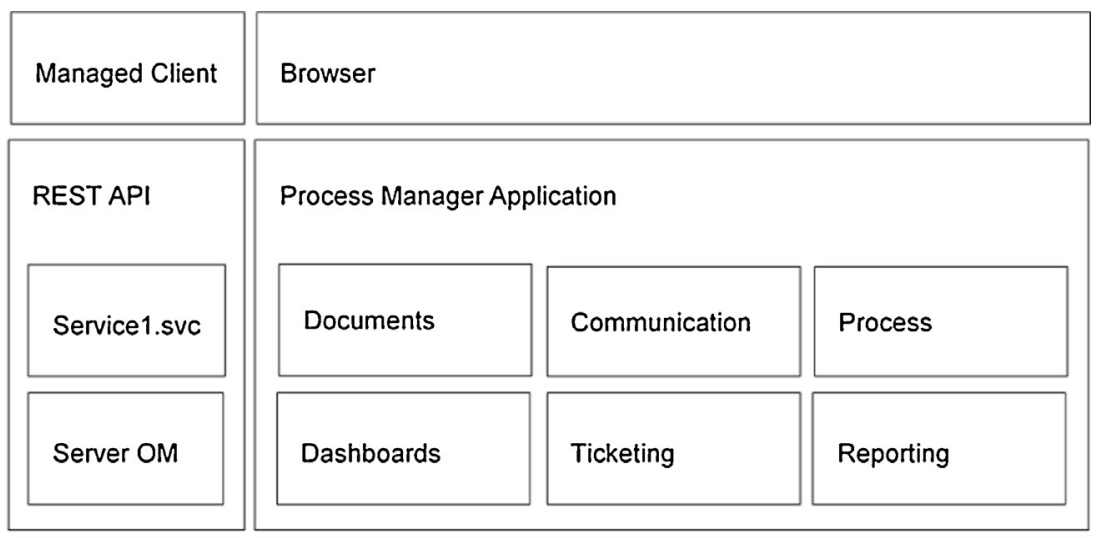

\section{SharePoint Foundation 2010}

\begin{tabular}{|l|l|l|l|}
\hline Content manager & $\begin{array}{l}\text { Administration } \\
\text { and Management } \\
\text { Shell }\end{array}$ & Web parts \\
\hline $\begin{array}{l}\text { Service } \\
\text { Application } \\
\text { Framework }\end{array}$ & $\begin{array}{l}\text { Lists, Libraries, } \\
\text { Content Types } \\
\text { and Field Types }\end{array}$ & $\begin{array}{l}\text { Site Templates } \\
\text { and Definitions }\end{array}$ & $\begin{array}{l}\text { Security, Claims } \\
\text { and Identity }\end{array}$ \\
\hline
\end{tabular}

SQL Server $2012 \quad \begin{gathered}\text { IIS7 asp.net } \\ 3.5\end{gathered}$

Windows Server 2012

Fig. 11. Overview of the architecture of the solution. 


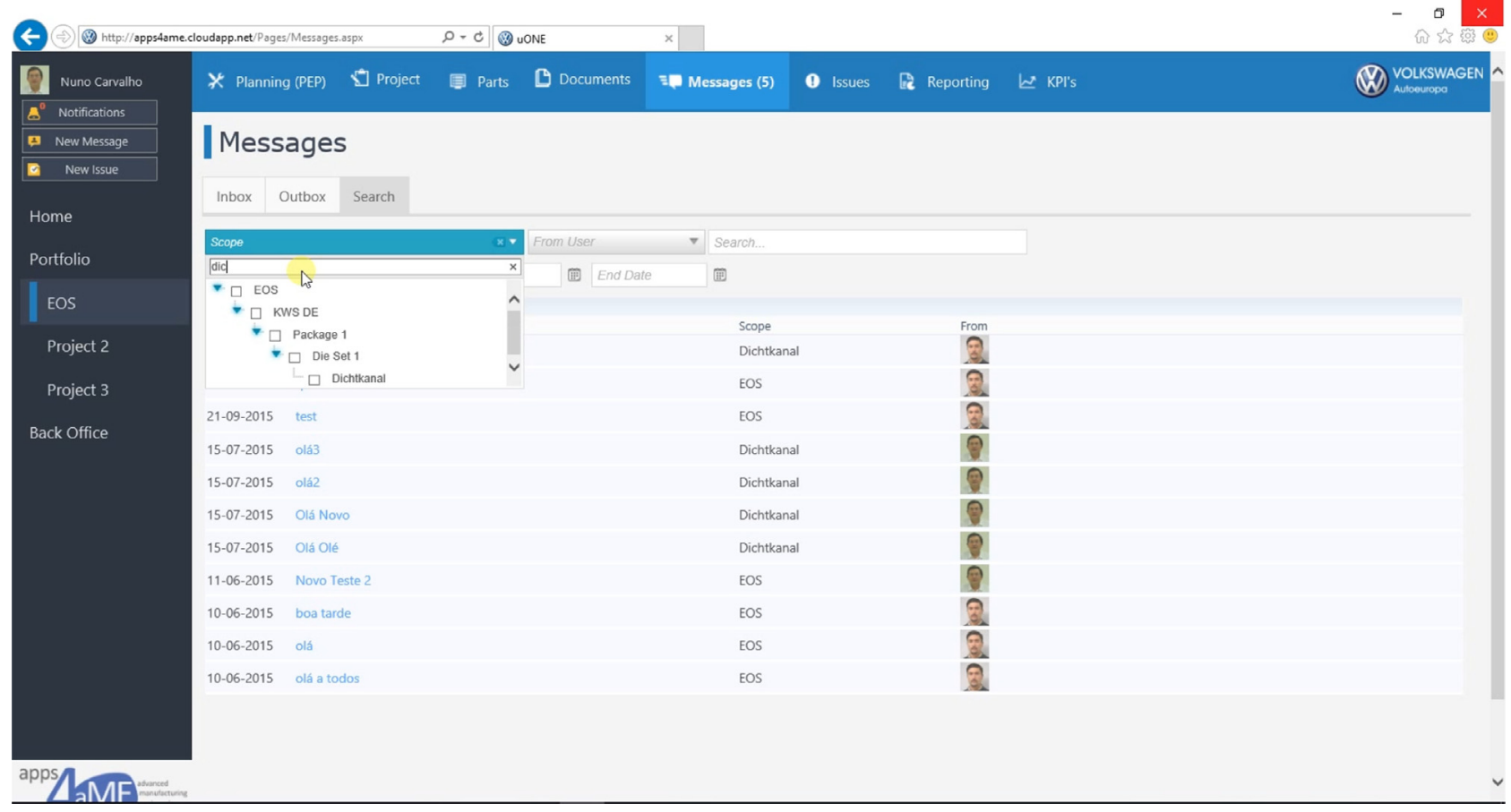

Fig. 12. Technical integration with Windows and office tools, which are widely used by project teams.

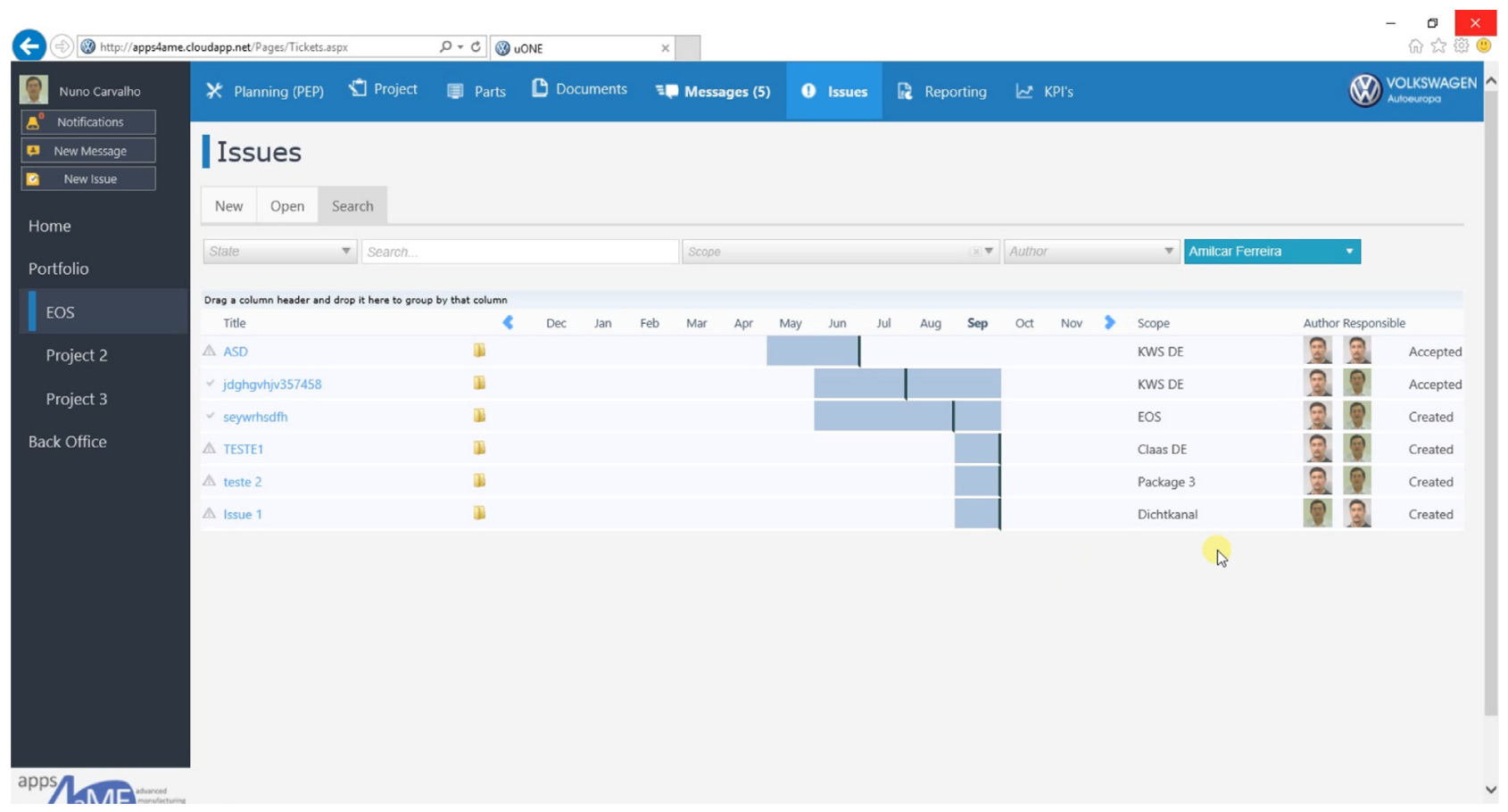

Fig. 13. Integrated communication/messaging along the process activities in the scope of each project/phase/to-do, eliminating the internal and project related email.

This solution has proven to be very effective and efficient when applied in hybrid work systems and in particular in the mechatronics engineering collaborative processes.
In summary, the project has improved the communication, the cooperation and trust the exchanged information, which are key factors for a successful project. In future, with the integration of suppliers, the solution aims to allow a chain reaction and a huge 


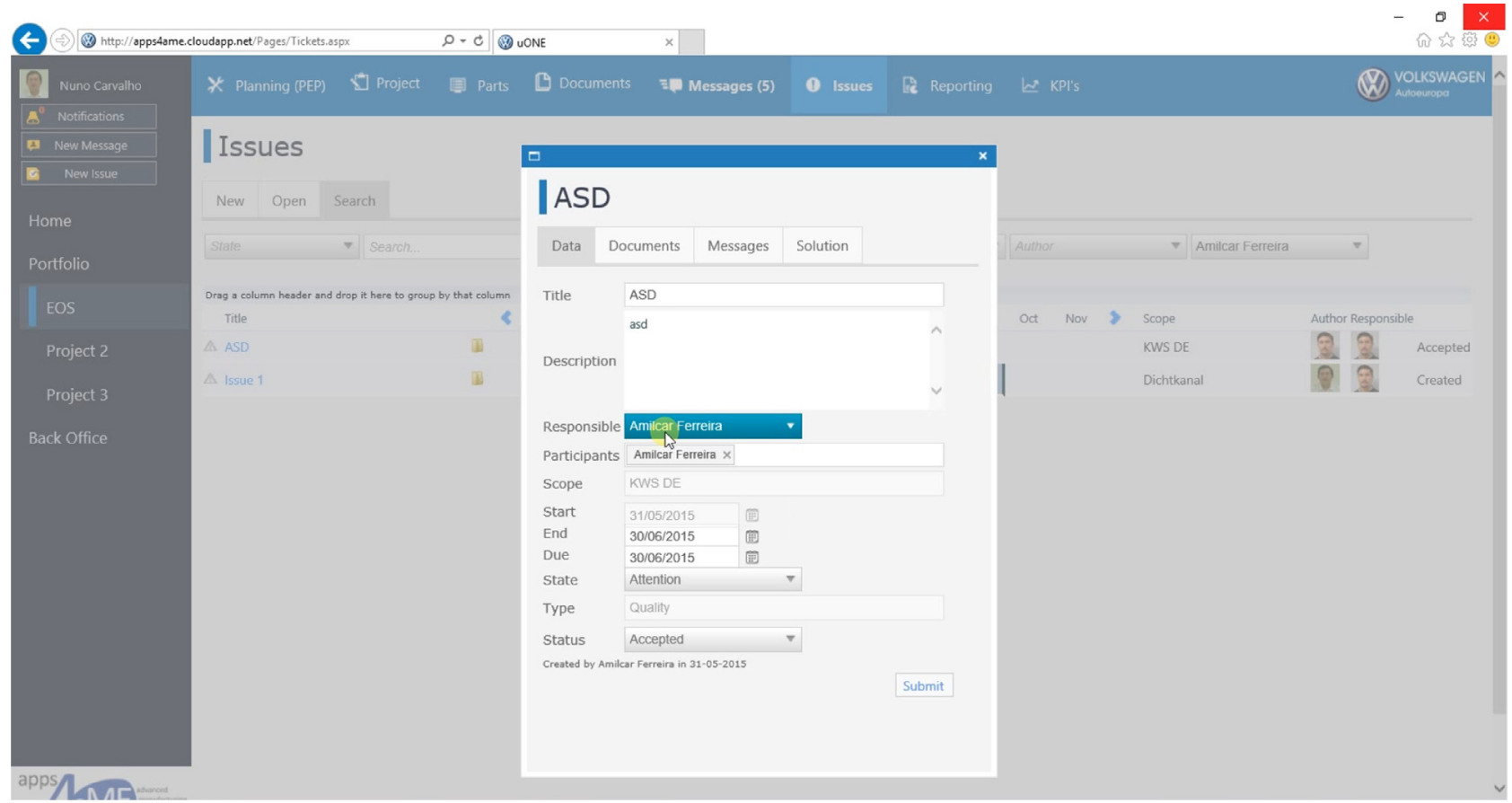

Fig. 14. Problem solving support, including tickets management integrated with all entities.

impact on speeding up the product development and time to market allowing also a faster response to external changes.

\section{Acknowledgements}

The research leading to these results has received funding from the European Union Seventh Framework Programme (FP7/20072013) under grant agreement $n^{\circ} 314156$. This work is co-financed by National Funds through the FCT - Fundação para a Ciência e a Tecnologia. The authors would also like to thank INESC TEC for their support.

\section{References}

Adams, M., Hofstede, A. H. M., Edmond, D., \& Van Der Aalst, W. M. P. (2006) Implementing Dynamic Flexibility in Workflows using Worklets.

Almeida, A., Ferreira, F., Azevedo, A., \& Caldas, Á. (2013). Process performance assessment in collaborative manufacturing environments: a role oriented approach. Advances in sustainable and competitive manufacturing systems. pp. 911-924. Springer International Publishing.

Andersson, B., Bider, I., \& Perjons, E. (2005). Business process support as a basis for computerized knowledge management. In Althoff, Althoff, et al. (Eds.), WM 2005, LNAI 3782 (pp. 542-553). Berlin, Heidelberg: Springer-Verlag.

Azevedo, A., \& Almeida, A. (2011). Factory templates for digital factories framework. Robotics and Computer-Integrated Manufacturing, 27, 755-771.

Azevedo, A., Faria, J., \& Ferreira, F. (2014). A framework to support the lifecycle of virtual manufacturing enterprises. In Proceedings of the 24th international conference on flexible automation \& intelligent manufacturing FAIM.

Brocke, J. V., Becker, J., Braccini, A. M., Butleris, R., Hofreiter, B., Kapočius, K., et al. (2010). Current and Future Issues in BPM Research: A European Perspective from the ERCIS Meeting 2010. Journal of the Association for Information Systems, 28(1), 393-414.

Carneiro, L., Almeida, R., Lopes Azevedo, A., Kankaanpaa, T., \& Shamsuzzoha, A. H. M. (2010). An innovative framework supporting SME networks for complex product manufacturing. Collaborative Networks for a Sustainable World, 336, 204-211.

Chryssolouris, G., Mourtzis, D., Papakostas, D., Papachatzakis, V., \& Xeromeritis, S. (2008a). Knowledge management in selected manufacturing case studies, methods and tools for effective knowledge life-Cycle-Management. In A. Bernard, \& S. Tichkiewitch (Eds.), (pp. 521-532). Springer [Part 3].

Chryssolouris, G., Mourtzis, D., Papakostas, D., Papachatzakis, V., \& Xeromeritis, S. (2008b). Knowledge management in selected manufacturing case studies. In A. Bernard, \& S. Tichkiewitch (Eds.), Methods and tools for effective knowledge life-Cycle-Management (pp. 521-532). Springer [Part 3].
Constantinescu, C., Hummel, V., \& Westkämper, E. (2006). The migration of the life cycle paradigm into the manufacturing engineering. Stuttgart: Institut für Industrielle Fertigung und Fabrikbetrieb.

Doumeingts, G. (1984). Méthode GRAI: Méthode de conception des systèmes de productique. These d'état en Automatique. Universite de Bordeaux I.

Paola Soto Rojas, E., Barros, A. C., de Azevedo, A. L., Batocchio, A., et al. (2012). Business model development for virtual enterprises. Collaborative networks in the internet of services. pp. 624-634. Berlin, Heidelberg: Springer.

Eversheim, W., Rozenfeld, H., Bochtler, W., \& Graessler, R. (1995). A methodology for an integrated design and process planning based on a concurrent engineering reference model. Annals of the CIRP, 44(1), 403-406.

Faria, J., \& Nóvoa, H. (2015). An agile BPM system for knowledge-Based service organizations. In in exploring services science, 6th international conference, IESS 2015 (pp. 65-79)

Faria, J., Silva, J., \& Marques, H. (2010). Supporting the operation of semi-structured work systems. In in enterprise information systems, international conference, CENTERIS 2010 (pp. 416-425)

Ferreira, F., Shamsuzzoha, A., Azevedo, A., \& Helo, P. (2015). Virtual enterprise process monitoring: an approach towards predictive industrial maintenance. Progress in Systems Engineering. pp. 285-291. Springer International Publishing.

Ferreira, F., Marques, A. L., Faria, J., \& Azevedo, A. (2016). Large project management in the automotive industry. A flexible and knowledge based approach?accepted as full paper for presentation at WorldCIST 2016 conference.

Grote, K.-H., \& Feldhusen, J. (2007). DUBBEL Taschenbuch für den Maschinenbau (22nd ed.). Berlin, Heidelberg: Springer Verlag.

Hill, C., Yates, R., Jones, C., \& Kogan, S. L. (2006). Beyond predictable workflows: enhancing productivity in artful business processes. IBM Systems Journal, 45(4), 663-682.

Jørgensen, H. D. (2001). Interaction as a framework for flexible workflow modelling. Colorado, USA: ACM GROUP'01. September 30-October.

Jiang, Y., Peng, G., \& Liu, W. (2010). Research on ontology-based integration of product knowledge for collaborative manufacturing. International Journal of Advanced Manufacturing Technology, 49(9), 1209-1221.

Kammer, P. J., Bolcer, G. A., Taylor, R. N., Hitomi, A. S., \& Bergman, M. (2000). Techniques for supporting dynamic and adaptive workflow. Computer Supported Cooperative Work (CSCW), 9(3-4), 269-292.

Kemppilä, S., \& Mettänen, P. (2004). Innovations in Knowledge Intensive Services. In: Innovations in Knowledge Intensive Services, pp. 22-25.

Kim, K.-Y., Chin, S., Kwon, O., \& Darin Ellis, R. (2009). Ontology-based modeling and integration of morphological characteristics of assembly joints for network-based collaborative assembly design. Artificial Intelligence for Engineering Design Analysis and Manufacturing, 23(1), 71-88.

Lu, R., Sadiq, S., \& Governatori, G. (2009). On managing business processes variants. Data \& Knowledge Engineering, 68(7), 642-664.

Makris, S., Michalos, G., Efthymiou, K., Georgoulias, K., Alexopoulos, K., Papakostas, N., et al. (2010). Flexible assembly technology for highly customisable vehicles (APMS 10). In International conference competitive and sustainable manufacturing, products and services.

Mangan, P., \& Sadiq, S. (2002). On building workflow models for flexible processes. Journal of Australian Computer Science Communications, 24(2), 103-109. 
Moody, P., Gruen, D., Muller, M., Tang, J., \& Moran, T. (2006). Business activity patterns: a new model for collaborative business applications. IBM Systems Journal, 45(4).

Mourtzis, D., Efthymiou, K., \& Papakostas, N. (2011). Product cost estimation during design phase. In 44th CIRP international conference on manufacturing systems.

Pahl, G., Beitz, W., \& Wallace, K. (2007). Engineering design: a systematic approach. Berlin, Heidelberg: Springer Verlag.

Rojas, E., \& Azevedo, A. (2014). Pillars and elements to develop an open business model for innovation networks. Collaborative systems for smart networked environments. pp. 317-326. Berlin, Heidelberg: Springer.

SPECIES. (2005). Sustainable production systems evolving in competitive instable environmental scenarios. Available from: http://www.species.polimi.it/ (accessed 29.01.16)

Schenk, M., Wirth, S., \& Müller, E. (2010). Factory planning manual. Berlin, Heidelberg: Springer Verlag.

Shamsuzzoha, A., Ferreira, F., Azevedo, A., Faria, J., \& Helo, P. (2013). Business process monitoring and management in virtual enterprise through interactive user interface layer advances in sustainable and competitive manufacturing systems. pp. 451-464. Springer International Publishing.

Shamsuzzoha, A., Ferreira, F., Sven, A., \& Helo, P. (2014). Visualization functionality of virtual factories-an enhancement to collaborative business process management. ICEIS, 2.

Sharp, A., \& McDermott, P. (2001). Workflow modelling: tools for process improvement and application development. Boston, USA: Artech House.
Swenson, K. (2000). Workflow for the information worker, in workflow handbook 2001. In L. Fischer (Ed.), Workflow management coalition. Lighthouse Point Florida, USA: Future Strategies Inc.

Tolio, T., Ceglarek, D., ElMaraghy, H. A., Fischer, A., Hu, S. J., Laperrière, L., et al. (2010). SPECIES-co-evolution of products: processes and production systems. Annals of the CIRP: Manufacturing Technology, 59(2), 672-693.

van der Aalst, W. (2004). Business process management demystified: a tutorial on models, systems and standards for workflow management. In J. Desel, W. Reisig, \& G. Rozenberg (Eds.), ACPN 2003, LNCS 3098 (pp. 1-65). Berlin, Heidelberg: Springer-Verlag.

Weber, B., Reichert, M., \& Rinderle-Ma, S. (2008). Change patterns and change support features - enhancing flexibility in process-aware information systems. Data \& Knowledge Engineering, 66, 438-466.

Westkämper, E., \& Hummel, V. (2006). The Stuttgart Enterprise Model - Integrated Engineering of Strategic \& Operational Functions. Manufacturing Systems: Proceedings of the CIRP Seminars on Manufacturing Systems, 35(1), 89-93.

Wiendahl, H.-P., Wiendahl, H.-H., Duffie, N., Brieke, M., et al. (2007). Changeable manufacturing?classification, design and operation. Annals of the CIRP: Manufacturing Technology, 2007, 783-809.

Zelm, M., Kosanke, K., \& Vernadat, F. (1999). CIMOSA: enterprise engineering and integration. Comput. Ind., 40(2-3), 83-97. http://dx.doi.org/10.1016/S01663615(99)00016-0 